\title{
Replantation of Mature Teeth Without Endodontics in Monkeys
}

\author{
Carlos E. Nasjlett, Raul G. Gaffesse, and Walter A. Gastelit \\ Veterans Administration Hospital and The University of Michigan, \\ Ann Arbor, Michigan 48105, USA
}

The purpose of this study was to evaluate the histologic response after replantation of mature, developed teeth without endodontic treatment in monkeys. To serve as experimental controls, the other replanted teeth received endodontic treatment. No significant differences were noted in the rate and quality of periodontal tissues healing between the endodontically and the nonendodontically treated teeth in monkeys sacrificed at 5,7 , and 14 days, and at 1,2 , and 3 months after replantation. However, specimens obtained at 4, 6, 9, and 12 months showed that teeth replanted without endodontics developed periapical complications, whereas endodontically treated teeth did not.

\section{J Dent Res 57(4):650-658, April 1978.}

In the dental nomenclature, intentional replantation refers to the deliberate extraction of a tooth for the purpose of performing endodontic therapy and reinserting the tooth in the alveolar socket, ${ }^{1}$ whereas replantation is the reinsertion of a tooth in its socket after its complete avulsion as a result of trauma or accidental extraction. ${ }^{2}$ Previous studies from this laboratory have explored various aspects of intentional tooth replantation in adult rhesus monkeys. ${ }^{3-7}$ Further, using intentional tooth replantation as a model system, the effects of acrylic, ${ }^{8}$ and amalgam ${ }^{9}$ restorations on the periodontal membrane have been described.

Clinical and histological studies both of intentional tooth replantation and replantation of teeth without endodontic treatment have produced conflicting results. ${ }^{10-14}$ Independently, Knight et $\mathrm{al}^{10}$ and Rothschild et

Received for publication August 22, 1977.

Accepted for publication November 29, 1977.

Supported by the Medical Research Service of the Veterans Administration.

* Purina Monkey Chow, Ralston Purina Co., St. Louis, Mo.

$\dagger$ Nembutal Sodium R, $50 \mathrm{mg} / \mathrm{ml}$, Abbott Laboratories, Chicago, Il.

$\mp$ Kerr Pulp Canal Sealer, Kerr Manufacturing Co, Detroit, Mi. $\mathrm{al}^{11}$ have examined the tissue changes associated with the teeth and surrounding structures when endodontically and nonendodontically treated maxillary incisors were replanted in dogs. These authors found that the teeth with treated pulp chambers showed better tissue acceptance. They also found that a greater amount of root resorption seemed to occur in untreated replants. They suggested that necrotic produrts of the pulp were responsible for this. However, Miller, ${ }^{12}$ Costich et al, ${ }^{13}$ and Andreasen and $\mathrm{Hj}$ ørting-Hansen ${ }^{14}$ questioned the actual need of performing root canal therapy on those teeth which had a short extraoral period.

The purpose of the present study is to evaluate the histologic response after replantation of mature, developed teeth without endodontic treatment in monkeys.

\section{Materials and Methods}

The upper incisors of 10 adult male Rhesus monkeys (Macaca mulatta) with permanent dentition were used for the study. The monkeys were housed in individual cages in air-conditioned rooms and fed Purina Monkey Chow* with water ad libitum. The animals were anesthetized injecting pentobarbital sodium (Nembutal†) $30 \mathrm{mg}$ per kilogram of body weight, intravenously, by means of a 25-gauge needle. Preoperative radiographs were secured. The monkeys were properly draped and the face prepared with $\mathrm{pHisoHex}$ and Zephiran. The two maxillary central incisors were extracted and wrapped in gauze saturated with normal physiological saline solution. To serve as experimental control, the left incisor received endodontic treatment, being filled with guttapercha and root canal sealer (Kerr Pulp Canal Sealert). The tooth was then replanted in the socket with finger pressure. Care was taken to maintain the vitality of the periodontal membrane by keeping the tooth moist with saline solution. The tooth 
was replanted 20 minutes after extraction. The immobilization of the replanted tooth was obtained by cementing a common metal inlay into previously prepared cavities in both left central and left lateral incisors. Simultaneously, the right central incisor (experimental tooth) was unwrapped and replanted. The tooth was held in place by means of another metal inlay that splinted the right central to the right lateral incisor. The monkeys were given $100 \mathrm{mg}$ of oxytetracycline (Cosa Terramycin§) dissolved in 16 ounces of water daily for the first three days after replantation. The splints were removed 7 to 10 days after surgery.

At postoperative intervals of 3,7 , and 14 days and 1, 2, 3, 6, 9, and 12 months, the monkeys were sacrificed. The maxillary incisors and the surrounding tissues were dissected

$\S$ Cosa Terramycin R, Department of Veterinary Medicine, Pfizer, Inc., New York, NY. out in one block. The lateral incisors served as nontreated controls. The blocks were fixed in $10 \%$ buffered formalin solution, and decalcified in formic acid. Serial sections of the decalcified, paraffin-embedded tissues were cut routinely at 6 to $7 \mu$ in the mesial-distal direction, and stained with hematoxylin and eosin for histologic examination.

\section{Results}

Supporting Periodontal tisSUes.-In general, no significant histologic differences were noted in the rate and quality of the healing of the periodontal tissues between the endodontically treated and the nonendodontically treated teeth in monkeys sacrificed at 3, 7, and 14 days, and at 1,2 , and 3 months after replantation, following the same pattern of healing already described in detail. ${ }^{6}$ Briefly,

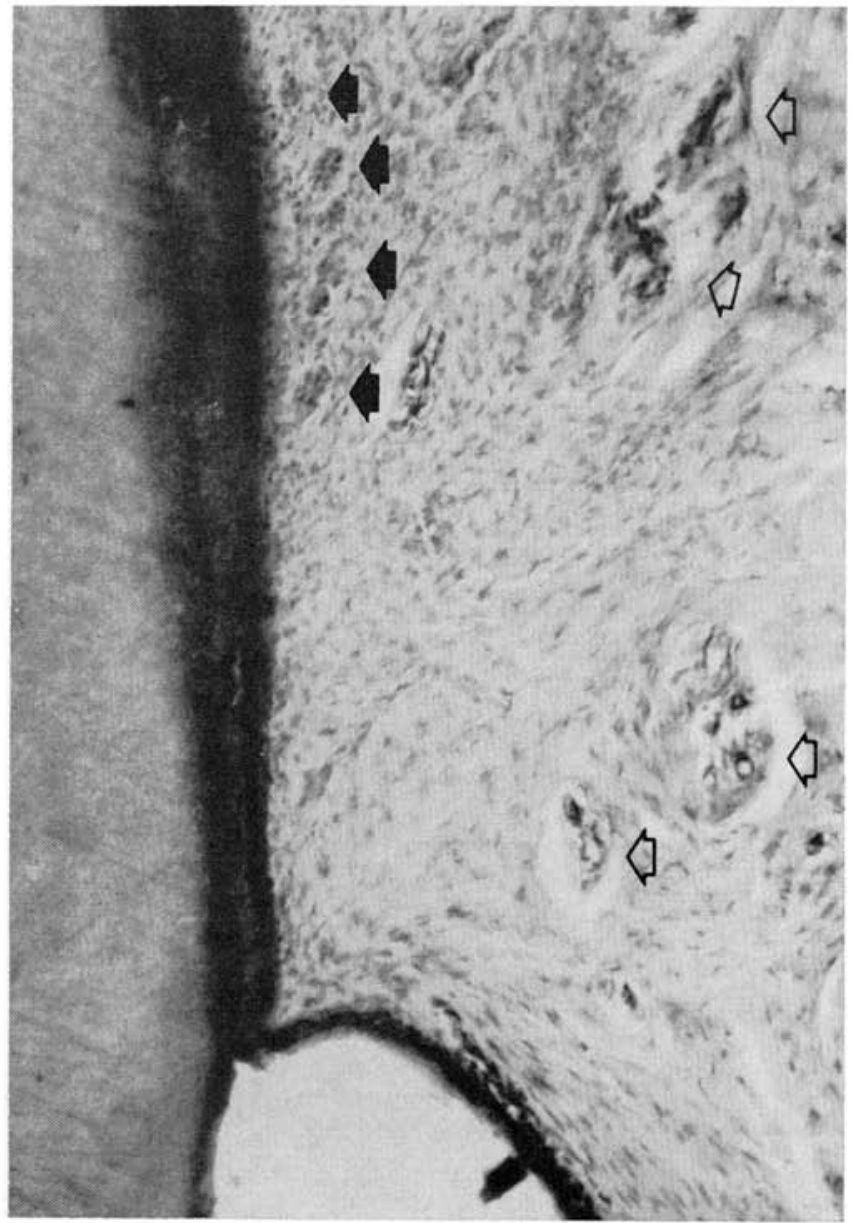

FIG 1. - Two weeks after tooth replantation. The junctional epithelial tissues showed normality. Epithelial rests of Malassez (solid arrows) were present mainly in the cervical third of the replanted root. Many sizable vessels (open arrows) were also noted. (H \& $\mathrm{E}$ stain; orig mag $\times 250$.) 
Fig 2.-In the one month replants the periodontal membrane had an almost normal appearance, but connective tissue maturity had not been achieved yet. The tooth on the left was replanted without prior endodontic treatment $(W E)$, whereas the tooth on the right was replanted after endodontic treatment $(E T)$. (H \& E stain; orig mag $\times 25$.)

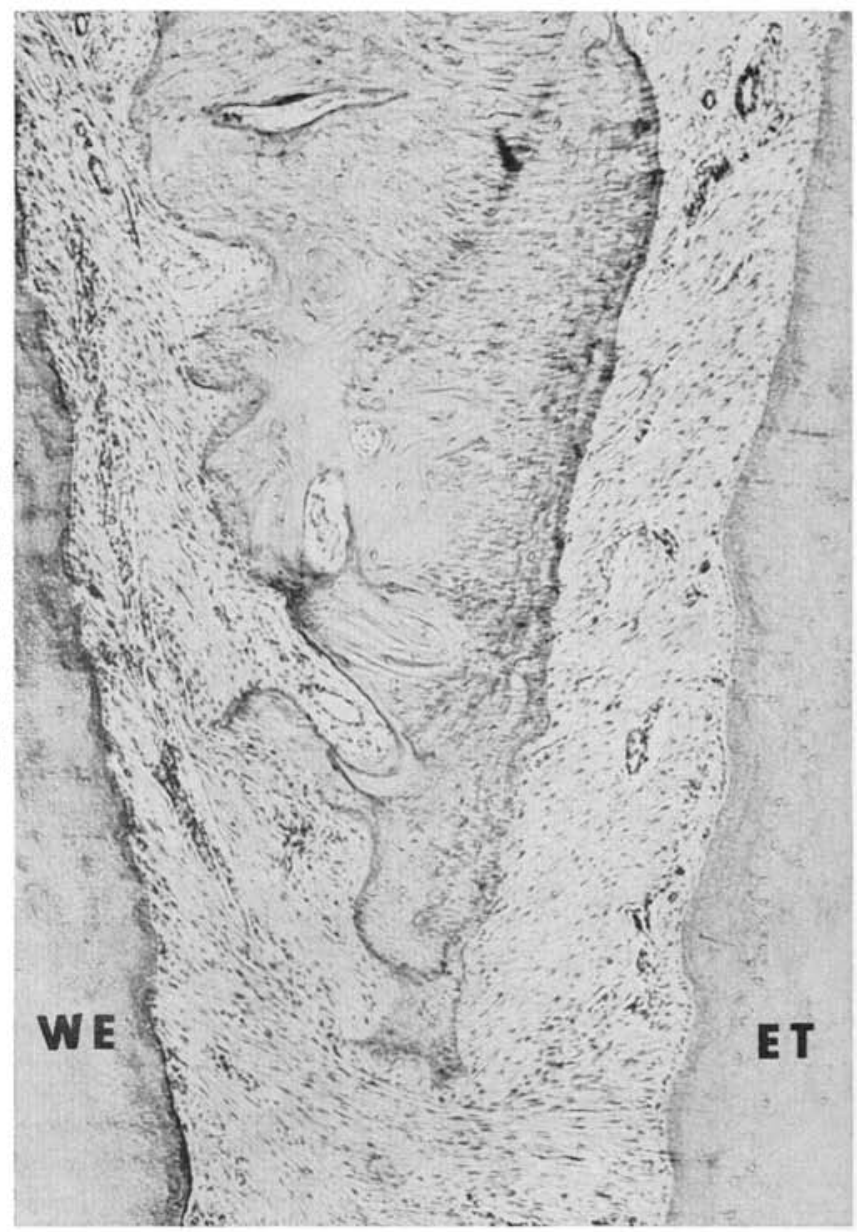

after three days the early fusion between the replanted teeth and the supporting connective tissue was mediated by a blood clot. Cementoblasts were absent. Histologic sections at 7 days showed a new junctional epithelium reestablished. The surgically created interfaces were undetectable, being replaced by young connective tissue which reestablished the continuity of the periodontal membrane and the supracrestal connective tissue. However, the young fibroblasts present were grossly disorganized, with no pattern of placement. In the 14day specimens the junctional epithelial tissues showed normality, whereas the supracrestal connective tissues were mildly infiltrated with chronic inflammatory cells. In the periodontal membrane space, fibroblastic activity was very pronounced and epithelial rests of Malassez were present mainly in the cervical third of the replanted roots. Many sizable vessels were noted in the center of the space. Cementoblasts were still absent (Fig 1). In the 1-month replants (Fig 2) the periodontal membrane had an almost normal appearance, but connective tissue maturity had not been achieved yet. The alveolar bone presented areas of both resorption and repair. Cementoblasts were present at this time, but isolated areas of lateral surface root resorption were detected. The 2-month and 3-month specimens (Fig 3) showed increased normality with time. No inflammatory cells were present within the confines of the periodontal membrane, although a number of round cells and lymphocytes were seen within the subsulcular area. No ankylosis or root resorption was observed, and apposition of cellular and acellular cementum was a frequent finding.

By contrast, histologic evaluation of the response of supporting tissue specimens ob- 
tained at 4, 6, 9, and 12 months showed an important significant difference. While the apical third of the teeth that were endodontically treated before replantation showed complete normality (Fig 4a), the teeth that were replanted without endodontics showed periapical complications. In each of these teeth a periapical granuloma surrounded the tooth apex (Fig 4b). It was composed mainly of round cells and endothelial cells enclosed in a fibrous capsule. Epithelial cell strands were also prominent. There has been resorption of the surrounding bone to accommodate the granuloma (Fig 5). The remaining periodontal tissues showed normal histological patterns both in treated and untreated teeth.

Pulpal tissues.-Pulpal changes were observed at various postoperative time intervals in those teeth that were replanted without endodontic treatment. Three days after replan- tation, pulpal edema, nuclear pyknosis and disintegration of the odontoblastic layer were seen. After 7 and 14 days, pulpal necrosis was confined to the coronal pulp chamber. Odontoblasts were absent and vacuolar degeneration and scarcity of fibrocytes were observed. The radicular canal showed signs of pulpal survival. In 3 months, the radicular pulp showed tendency to a normal histological picture. However, there was some disruption of the odontoblastic layer in areas associated with the irregular apposition of osteodentin. A thick layer of matrix was also visible (Fig 6). From 4 through 12 months, there was a progressive deterioration of the pulp tissues, leading to necrosis. Irregular and sparse distribution of odontoblasts, hyalinization of the central part of the pulp with vacuolar formation and fibrotic bands could be seen (Fig 7). In 12 months, there was a frank necrosis of the

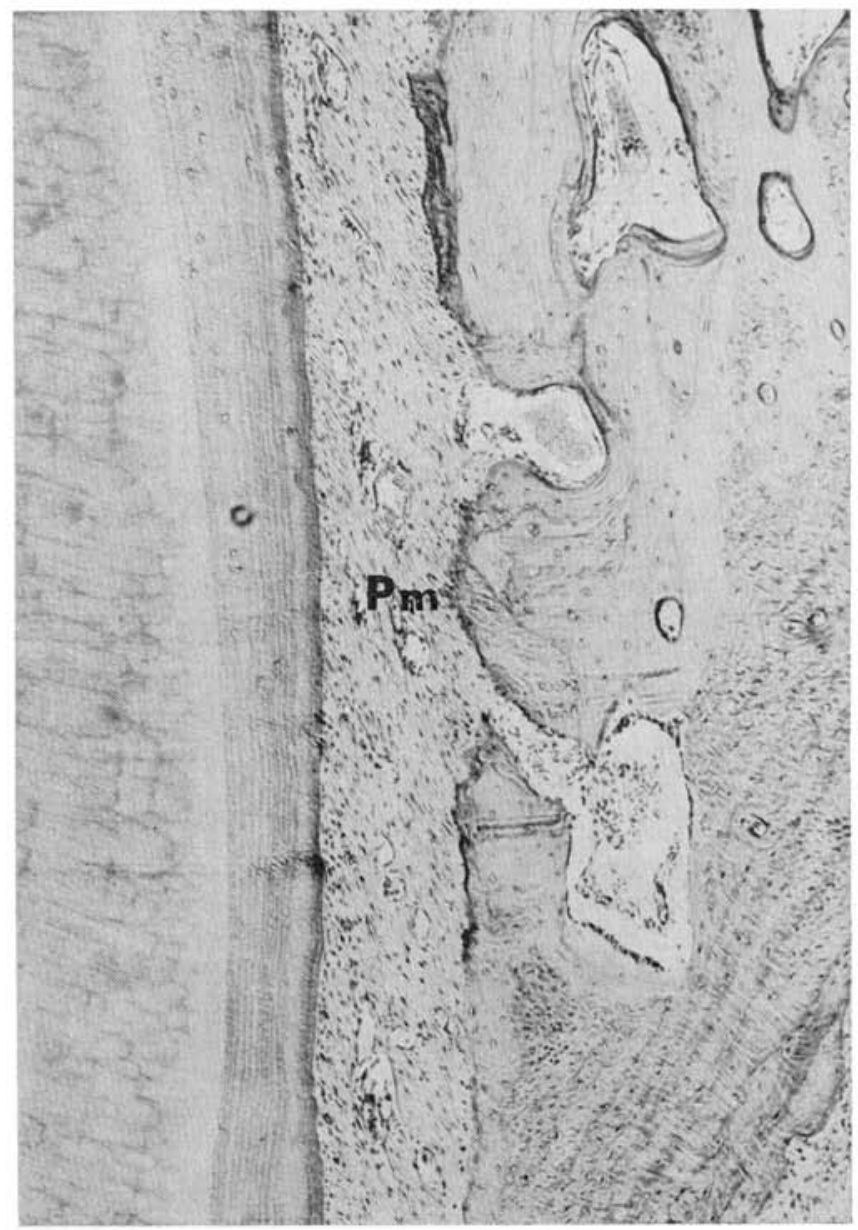

Fig 3.-Three months after tooth replantation. No inflammatory cells were present within the confines of the periodontal membrane $(\mathrm{Pm})$, and no ankylosis or root resorption was observed either. ( $\mathrm{H} \& \mathrm{E}$ stain; orig mag $\times 25$.) 


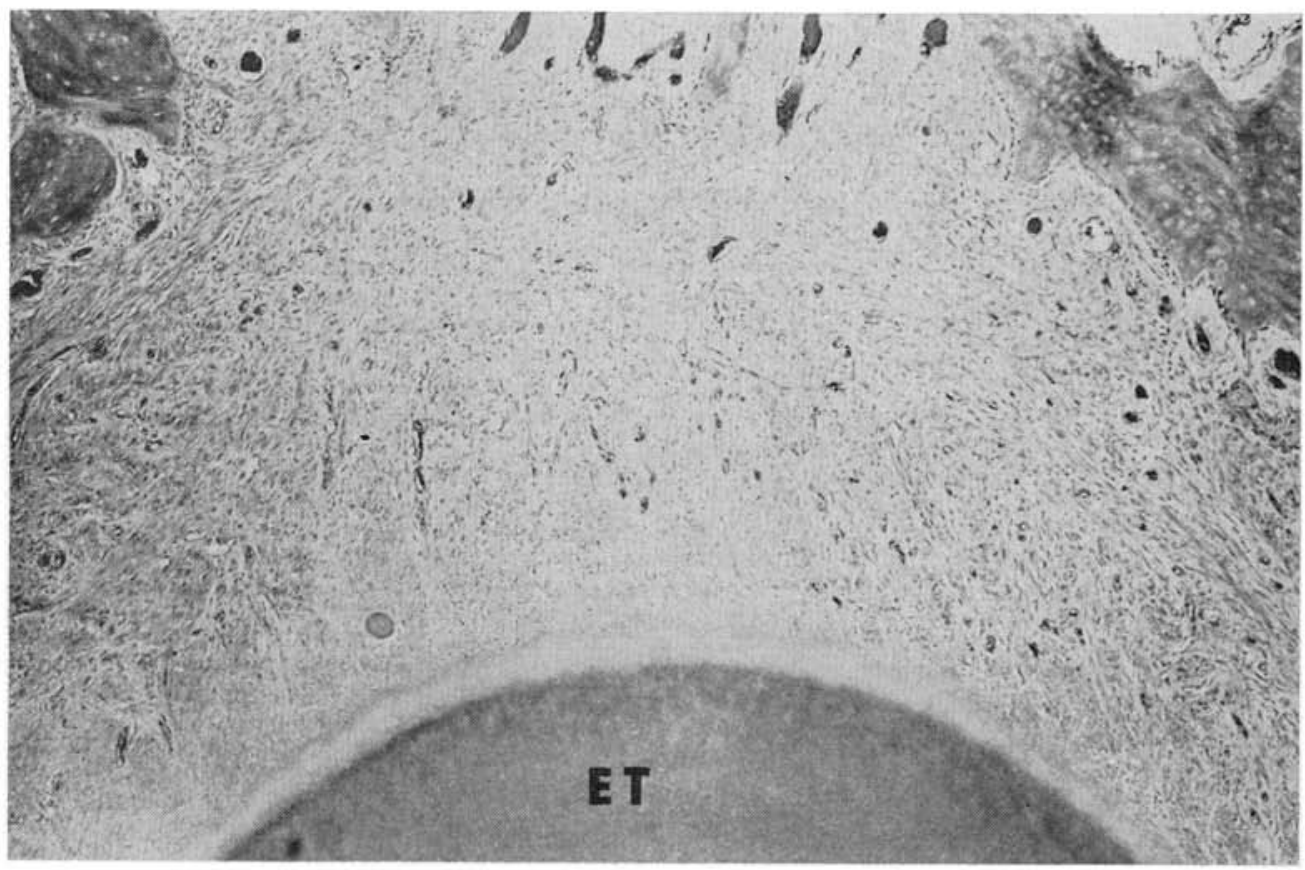

Fig 4a.-Four months after tooth replantation. The apical area of the tooth that was endodontically treated (ET) before replanta-

tion showed complete normality. (H \& E stain; orig mag $\times 125$.)

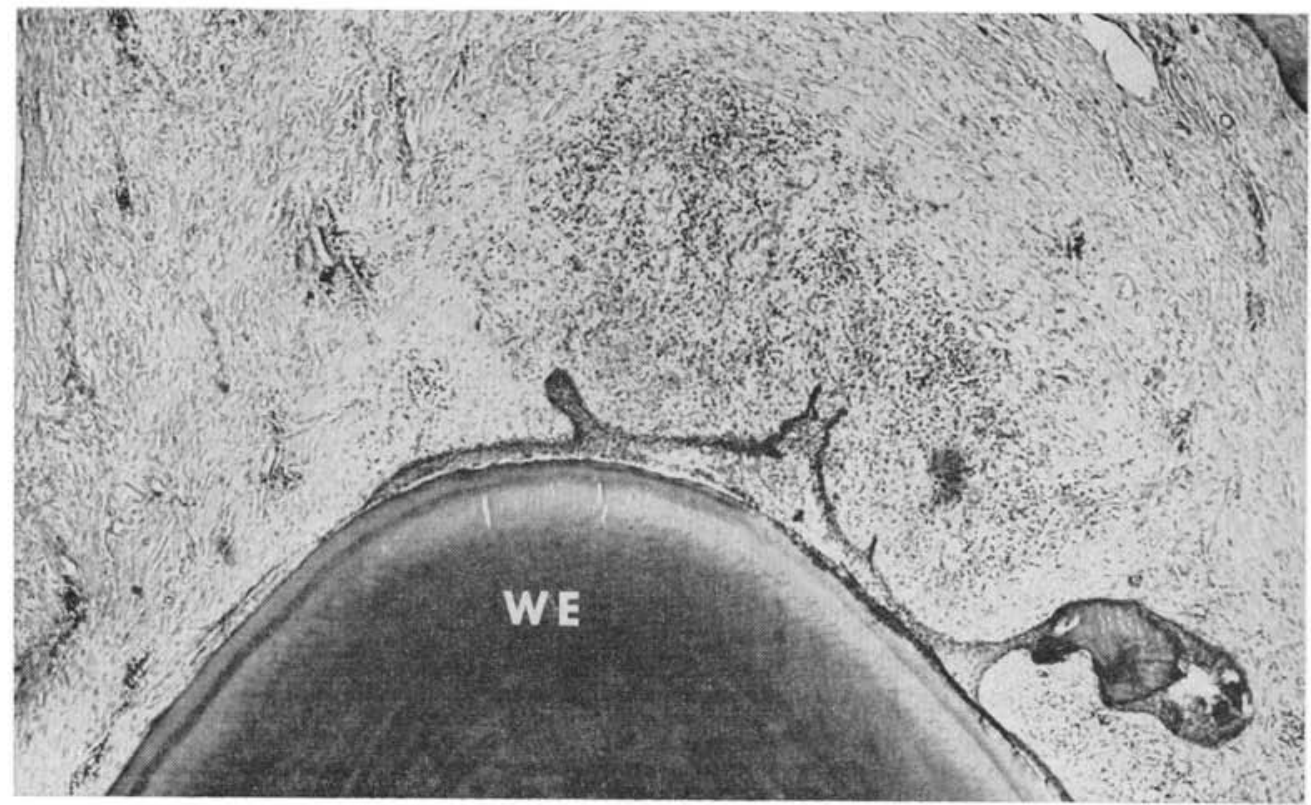

FIG 4b.--Four months after tooth replantation. The apical area of the tooth that was replanted without endodontics (WE) showed a granuloma. It was composed mainly of round cells and endothelial cells. Epithelial cell strands were also prominent. ( $\mathrm{H} \& \mathrm{E}$ strain; orig $\operatorname{mag} \times 125$.) 


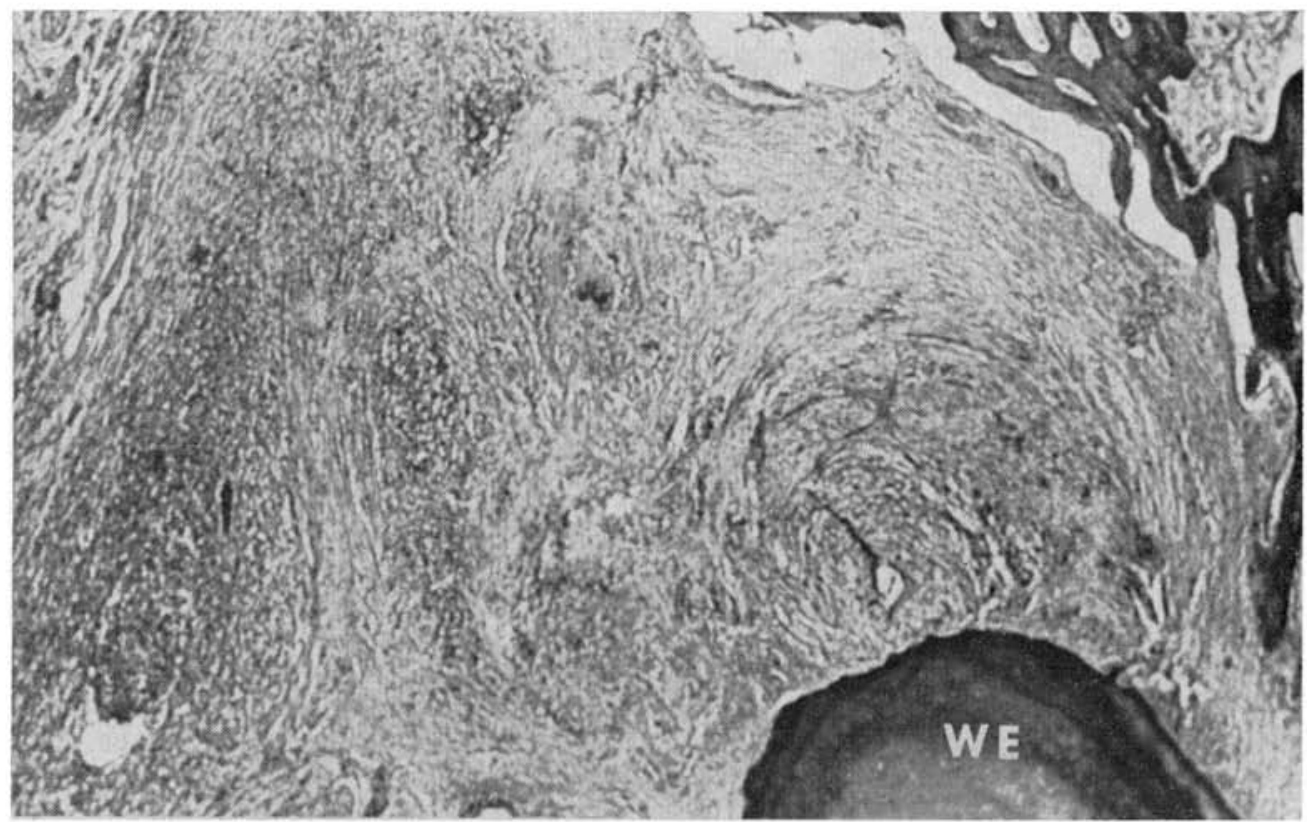

FIG 5.-Nine months after tooth replantation. The tooth that was replanted without endodontics $(W E)$ showed a periapical granuloma surrounding the tooth apex. There has been re- sorption of the surrounding bone to accommodate the granuloma. (H \& E stain; orig mag $X$ 125.)

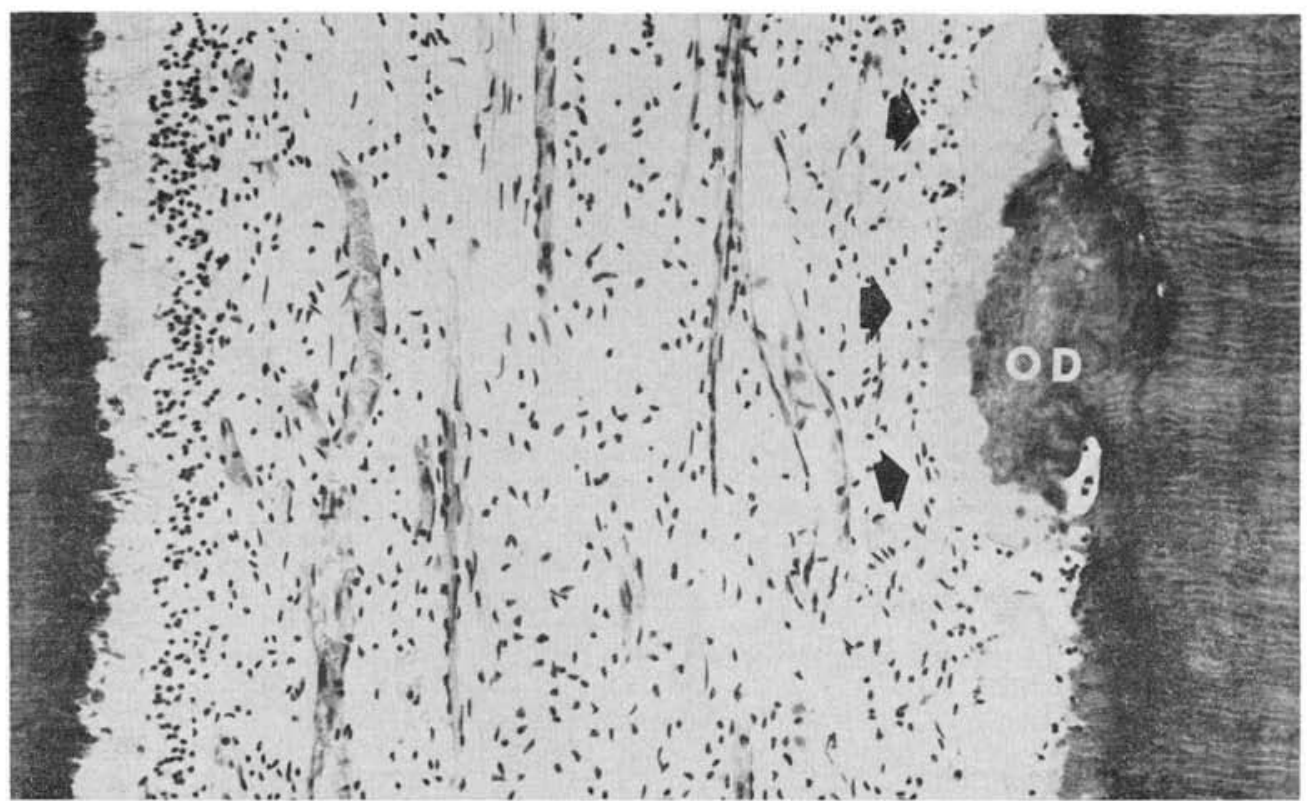

Fig 6.-Three months after replantation. The radicular pulp showed tendency to a normal histological picture. However, there was some disruption of the odontoblastic layer in areas associated with the apposition of osteodentin $(O D)$. A thick layer of matrix was also visible (solid arrows). (H \& E stain; orig mag $\times 250$.) 
pulp accompanied by the periapical changes already described (Fig 8).

\section{Discussion}

Our observations have confirmed previous histologic studies ${ }^{10,11,15}$ of more favorable results when root canal treatment was used prior to replantation. Knight et al ${ }^{10}$ found that the teeth with treated pulp chambers showed better tissue acceptance. They also found that a greater amount of root resorption seemed to occur in untreated replants, suggesting that necrotic products from the pulp were responsible for it. They suggested also that replanted teeth should have root canal therapy as close to the time of replantation as possible. Results of the study by Rothchild et al $^{11}$ showed almost identical findings. More recently, Woehrle ${ }^{15}$ studied reparative cementum differences in replanted teeth of dogs treated by endodontics and without pulpal treatment. When evaluated for periapical pathosis, the majority of teeth with endodontic treatment were graded as having minimal pathological findings, whereas teeth with no treatment were usually associated with granulomas of variable severity.

It is interesting to note that root canal therapy prolonged the survival even in transplants of tooth allographs. Feingold et $\mathrm{al}^{16}$ conducted a study to determine the effect of pretransplant endodontics on tooth allograph survival in monkeys. The study showed that pretransplant root canal therapy eliminated the synergism of the periapical-periodontal inflammation which often characterized tooth allograph rejection, and which enhanced the rapid inflammatory resorption of supporting bone and tooth structure. They concluded that "pretransplant endodontics may well be the most significant phase of donor tooth treatment." A review of recent research in the area of implants and transplants has been published by Boyne, ${ }^{17}$ and referring to tooth replantation, he stated: "Immediate endodontic therapy seems to be necessary in reimplantation surgery involving completely avulsed teeth with fully formed roots, and in all instances in which a considerable time has elapsed between

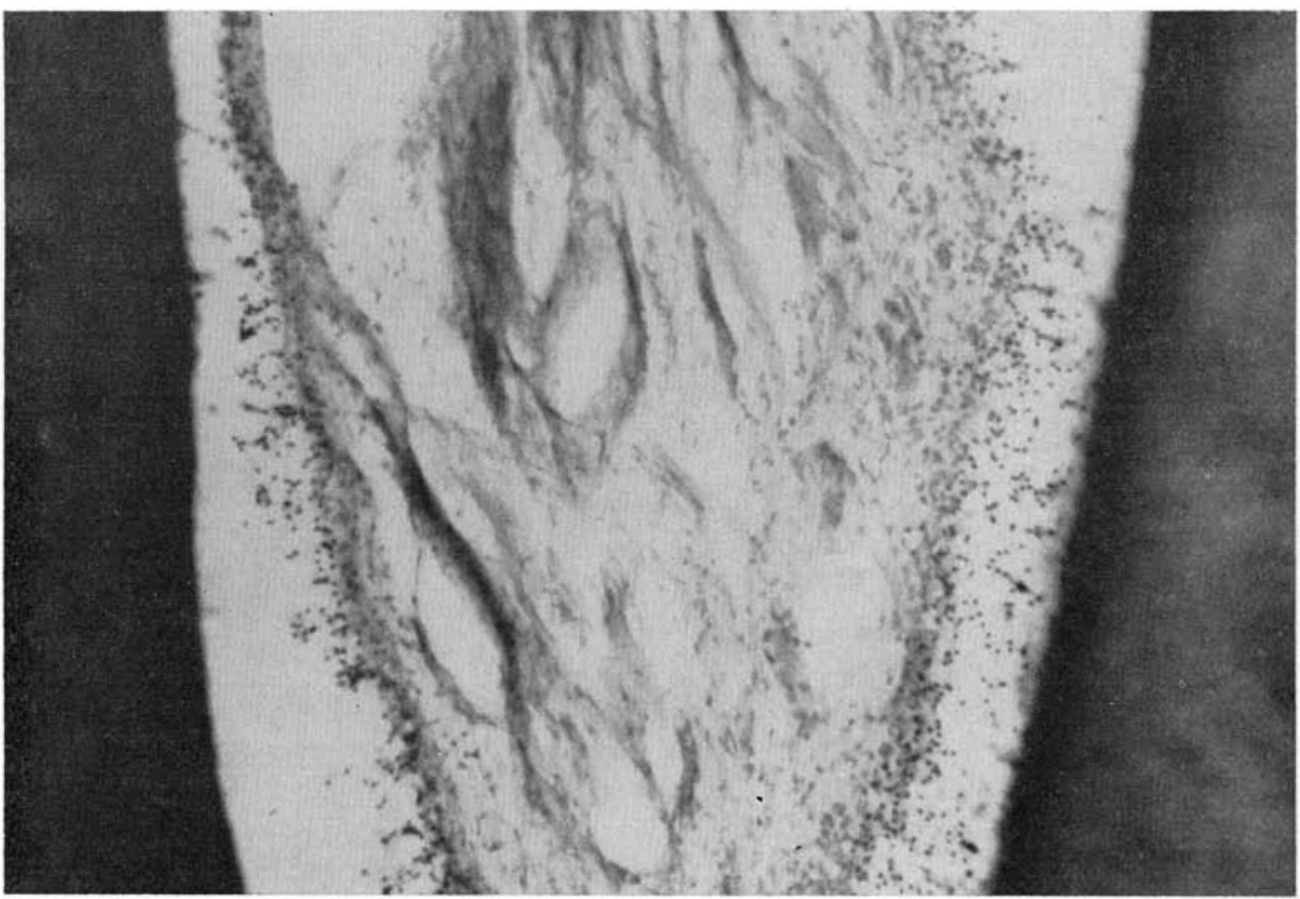

FIG 7.-Nine months after replantation. Irregular and sparse distribution of odontoblasts, hyalinization of the central part of the pulp with vacuolar formation, and fibrotic bands could be seen. (H \& E stain; orig mag $\times 250$.) 


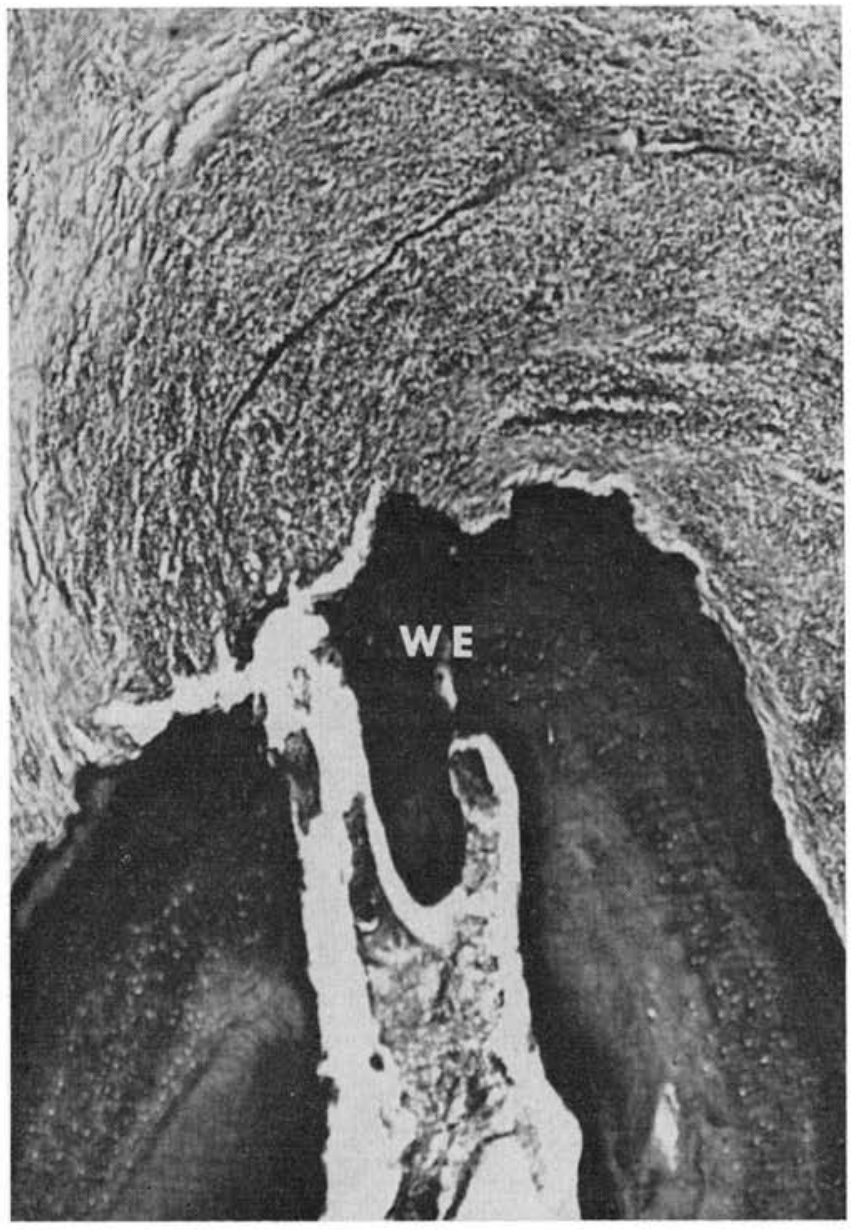

FIG 8.-Twelve months after replantation. The tooth that was replanted without endodontics (WE) showed a necrotic pulp accompanied by a periapical granuloma. (H \& E stain; orig mag $\times 125$.) the accidental avulsion of the teeth and the institution of treatment."

The replantation of mature, developed teeth without root canal therapy may appear attractive to the clinician by the ease of the procedure as compared to the endodontically treated teeth. From a biological point of view, however, the nontreatment of teeth results in partial failure. Similar agreement is encountered in early publications as well. ${ }^{12}{ }^{\prime} 13$ Miller ${ }^{12}$ stated, "A tooth with a partly formed root may be replanted immediately without root canal therapy, but a mature tooth may require root canal treatment before reinsertion." His observations were similar to those of Costich et al, ${ }^{13}$ who would emphasize the words "may require root canal treatment" when talking of "mature teeth" in young adults. Clinically, then, it is worth suggesting that the periodontal mem- brane is the tissue to be saved and protected even at the expense of the pulp tissues in replantation of mature, developed teeth. Frequency of channels of communication between the pulp and the periodontal membrane through accessory canals has been widely documented. ${ }^{10,11}$ This possibility should not be overlooked as an enhancing factor contributing to the chronic process observed in the 4-, 6-, 9-, and 12-month nontreated specimens of the present study.

\section{Summary and Conclusions}

An experimental model was devised to study, in monkeys, the histologic response after replantation of mature, developed teeth without endodontic treatment. To serve as experimental controls, other replanted teeth received 
root canal treatment. No significant histologic differences were noted in the rate and quality of healing between the endodontically treated and the untreated teeth in monkeys sacrificed at 3, 7, and 14 days, and at 1, 2, and 3 months after replantation. This indicated that the replantation procedures used did not alter the early reaction to acute trauma produced both by extraction of the tooth and replantation of it. However, histologic evaluation of specimens obtained at 4, 6, 9, and 12 months showed an important significant difference. Teeth replanted without root canal treatment developed periapical complications, whereas endodontically treated teeth did not. Furthermore, pulpal changes leading to necrosis were also observed at various time intervals in those teeth that were replanted without endodontics. Thus, it is worth suggesting that the periodontal membrane is the tissue to be saved and protected even at the expense of the pulp tissue in replantation of mature, developed teeth.

\section{References}

1. Dees, E.: Intentional Replantation of Endodontically Treated Teeth, in: Transactions of the Fourth International Conference on Endodontics, Philadelphia: University of Pennsylvania, 1968, pp 147-157.

2. GROSSMAN, L.I.: Intentional Replantation of Teeth, J Am Dent Assoc 72:1111-1118, 1966.

3. Castelli, W.A.; Nasjleti, C.E.; Huelke, D.F.; and Diaz-Perez, R.: Revascularization of the Periodontium after Tooth Grafting in Monkeys, $J$ Dent Res 50:414-421, 1971.

4. Keller, B.E.; Hayward, J.R.; Nas Jleti, C.E.; and Castelli, W.A.: Venous Tissue Replanted on Roots of Teeth in Monkeys, Oral Surg 34:352-363, 1972.

5. NAS Jleti, G.E.; Castelli, W.A.; and Blankenship, J.R.: The Storage of Teeth before Reimplantation in Monkeys, Oral Surg 39:20-29, 1975.
6. Nasjleti, G.E.; Caffesse, R.G.; CasTELLI, W.A.; and HoKE, J.A.: Healing after Tooth Reimplantation in Monkeys, Oral Surg 39:361-375, 1975.

7. Caffesse, R.G.; Nasjleti, C.E.; and CasTELLI, W.A.: Long-term Results after Intentional Tooth Reimplantation in Monkeys, Oral Surg 44:666-678, 1977.

8. Nas jleti, G.E.; Castelli, W.A.; and KelLER, B.E.: Effects of Acrylic Restorations on the Periodontium of Monkeys, J Dent Res 51 Part 2: 1382-1387, 1972.

9. Nas Jleti, G.E.; Gastelli, W.A.; and GafFESSE, R.G.: Effects of Amalgam Restoration on the Periodontal Membrane in Monkeys, J Dent Res 56: 1127-1131, 1977.

10. Knight, M.K.; Gans, B.J.; and CalanDRA, J.C.: The Effect of Root Canal Therapy on Replanted Teeth of Dogs, Oral Surg $18: 227-242,1964$.

11. Rothschild, D.L.; Goodman, A.A.; and BLAKEy, K.R.: A Histologic Study of Replanted and Transplanted Endodontically and Nonendodontically Treated Teeth in Dogs, Oral Surg 28:871-876, 1969.

12. Miller, H.M.: Transplantation and Reimplantation of Teeth, Oral Surg 9:84-95, 1956.

13. Costich, E.R.; Haley, E.; and Hoek, R.: Plantation of Teeth, A Review of the Literature, New York St Dent J 29:3-13, 1963.

14. Andreasen, J.O., and Huorting-Hansen, E.: Replantation of Teeth; 1. Radiographic and Clinical Study of 110 Human Teeth after Accidental Loss, Acta Odontol Scand $24: 263-286,1966$.

15. Woemrle, R.R.: Cementum Regeneration in Replanted Teeth with Differing Pulp Treatment, J Dent Res 55:235-238, 1976.

16. Feingold, R.M.; Hovinga, J.; Millstein, C.; and Shulman, L.B.: Prolonged Survival of Rhesus Tooth Allographs by Pretransplant Endodontics, IADR Abstracts, Abstract No. 594, 1971.

17. Boyne, P.J.: Implants and Transplants: Review of Recent Research in This Area of Oral Surgery, J Am Dent Assoc (Special Issue) 87:1074-1080, 1973. 